\title{
College Student Development within the Context of Formalized Sport in American Higher Education
}

\author{
Daniel Springer and Marlene A. Dixon \\ Texas A\&M University
}

\begin{abstract}
To this point research on formalized sport in American higher education (i.e., recreational sport and collegiate athletics) has been limited in its conception of college student development which has limited its influence on the design and implementation of college and university sport programs. Expanding how college student development is understood would enable sport scholars to examine a wider array of educational and developmental outcomes within the college sport landscape. Not only would this fundamentally shift the type of questions asked of and about formal sport environments, it might also change how sport managers conceptualize and mobilize sport in higher education. This paper provides a foundational starting-point for sport scholars to diversify their approach to advance the study of college student development within formalized sport environments in American higher education.
\end{abstract}

Keywords: college student development, student development theory, intercollegiate athletics, recreational sport, sport clubs, intramurals

Despite its complexity, sport is often portrayed as monolithic. The prevailing assumption is that sport, as an entity, is inherently good and that, through participation alone, individuals will progress in various domains (e.g., physically, socially, morally; Coakley, 2015; Warner \& Dixon, 2013; Warner, Dixon, \& Chalip, 2012). Yet, in practice, actualizing the developmental potential of sport programs, particularly within an American context that often entangles sport and education (Ridpath, 2018), requires intentional design and implementation on the part of sport managers (Beyer \& Hannah, 2000; Patriksson, 1995; Schulenkorf, Sherry, \& Phillips, 2016). Educationally embedded sport programs, through their design and implementation, have an implicit responsibility to complement, or even enhance, the educational environment and to emphasize other non-sport outcomes (e.g., cognitive, social, emotional, moral, occupational, political).

To this point, however, research on formalized sport in American higher education (i.e., recreational sport and intercollegiate athletics) has been limited in its conception of college student development which, in turn, has limited its influence on the design and implementation of college and university sport programs. Expanding how sport scholars understand college student development would enable them to 
consider a wider array of educational and developmental outcomes within the college sport landscape. This would not only fundamentally shift the type of questions asked of and about formal sport environments but might also influence how sport managers conceptualize and mobilize sport in higher education.

Thus, the goal of this paper is to provide a foundational starting-point for sport scholars to diversify their approach to the study of formalized sport environments in American higher education. The remainder of the paper will provide a brief examination of relevant literature followed by a broad discussion of college student development, the theories that inform it, and potential questions those theories might generate that are necessary to continue this conversation.

Before proceeding to an examination of literature, however, it is important to first clarify two concepts undergirding the arguments presented in this paper. First, the sport context is discussed in this paper from a global perspective so, at times, examples may seem overly general. The authors appreciate the often subtle and nuanced situational differences from one geographic location to another, from one campus to another, from one division to another or even from one team to another within a single athletic department. Examples are provided not to be applied at a micro- or even meso-level of conceptualization but rather to highlight broader issues that may be present within the American college sport context. Second, it is not the aim of this paper to advocate for one domain of development over another, but instead to illustrate the diversity of theories available for inquiry into college student development which help to broaden the conceptual understanding of various developmental outcomes within the context of American higher education.

\section{Formalized Sport in American Higher Education}

The long and storied history of sport and American higher education would be difficult to comprehensively delineate here, given that its origins predate American independence (Brubacher \& Rudy, 1997; Hyatt, 1977; Ridpath, 2018; Stewart, 1992). For our purposes, though, it is important to understand that what began as intramural sport eventually unfolded into intercollegiate sport clubs which subsequently laid the foundation for the emergence of a varsity athletic system (Brubacher \& Rudy, 1997; Hyatt, 1977). Since the turn of the $20^{\text {th }}$ Century, however, each system has traversed vastly different trajectories to form three distinct formalized sport systems differentiated by their philosophies, structures, and desired outcomes.

\section{Varsity Sport Programs}

Philosophically, the structure and outcomes of National Collegiate Athletic Association (NCAA) athletic programs are driven by three main considerations: educational, commercial, and competitive (Nite, Singer, \& Cunningham, 2013; Snyder \& Waterstone, 2015; Southall, Hancock, Cooper, \& Nagel, 2009; Southall \& Nagel, 2008). These considerations likely vary in order and magnitude from program to program and certainly from division to division. For example, Snyder and Waterstone (2015) noted the diversity and quantity of institutions in Division III, emphasizing differ- 
ences in how athletic programs are funded and how they fit into the overall campus culture when compared to Division I or Division II institutions. A consistent theme amongst athletic departments' missions, regardless of division, is a student-centered approach to the design and implementation of their programs, although some have noted an incongruence between explicit goals and implicit expectations (Adler \& Adler, 1987; Jayakumar \& Comeau, 2016; Rubin \& Moses, 2017).

To be sure, there are a number of positive outcomes one can associate with participation in varsity athletic programs (Chen, Snyder, \& Magner, 2010). Examples might include the physical and intellectual (i.e., sport IQ) development needed to compete at the collegiate level, the ability to navigate new interpersonal relationships with teammates and coaches, the skills and strategies necessary to balance athletic and academic priorities or the unique opportunities and experiences one might access through athletic participation.

The varsity athletic environment is also unquestionably challenging. Participants are asked to adjust to a highly demanding academic and athletic schedule while simultaneously adapting to living away from home, possibly for the first time, creating new social networks and other challenges that accompany enrollment in higher education. As students persist, new challenges might arise with the realization that a professional athletic career is not feasible and that they must begin to prepare for employment that potentially relies on skills outside of their athletic abilities. The question, from a developmental perspective, then becomes how the varsity sport environment supports and hinders individual development.

From this perspective, the goal is not to eliminate all challenges, but to mitigate them to the extent that they push students without overwhelming them (Sanford, 1967). For example, a first-year college student may need assistance to plan their academic schedule, understand the registration process, or locate and attend all of their courses. Students that persist to their junior or senior year should no longer require this level of support. Certainly, this developmental progress should be seen in both athletes and non-athletes.

When varsity athletes are academically motivated, balancing academic and athletic demands may not cause issues because they are more likely to seek out their own path and take ownership of the process. If they are not particularly academically self-motivated, however, the extent to which they are pushed toward prioritizing (or even balancing) academics over athletics (which is implied by the use of terms like "student-athlete") will largely depend on the overall athletic environment. Athletic staff and administrators might only push students academically in so much as it ensures they maintain the minimum academic standards to remain eligible to compete and may over-provide academic support in a variety of ways that actually hinder athletes' ownership of their academic development.

In addition to managing academic schedules and needs, college students have other social roles that are important to holistic development. Managing additional roles can be particularly challenging as varsity programs are considered elite sport and therefore require students to commit a great deal of time and effort to their athletic development (Ayers, Pazmino-Cevallos, \& Dobose, 2012; Beyer \& Hannah, 
2000; Gayles, 2009a, 2009b, 2014; Wolverton, 2008). Thus, the importance of other non-sport developmental areas will also likely be viewed and managed in relation to how they help or hinder students' athletic progress (Anderson \& Dixon, 2019).

Thus, regarding the factors that form the overall environment in athletic programs, there are a number of layers that need to be examined to understand their role and implications. The more proximate layers consist of administrators, coaches, compliance staff, training staff, an individuals' teammates and, in some cases, academic support staff. More distal factors include instructors, university support staff, alumni, and what some refer to as normies or non-athletic regular people (NARPs) (Anderson \& Dixon, 2019). Exacerbating issues within these layers is the fact that oversight of varsity programs extends beyond the philosophies, rules, and regulations of the specific institutions they represent. External influence is exerted by athletic conferences and the NCAA. These bodies make decisions directly impacting the underlying philosophies that shape the athletic environment.

\section{Recreational Sport Programs}

Intramural and club sport programs, in contrast to varsity programs, are philosophically driven by a mixture of educational, accessibility, and competitive considerations and tend to fall within the purview of campus recreation departments that report to one of three administrative areas (i.e., academics, athletics, or student affairs; Schneider, Stier Jr., Kampf, Haines, \& Wilding, 2005). While exclusivity might be a hallmark of varsity athletics, "[c]ampus recreation programs have a mission of providing a variety of programs, open to all students, regardless of the participants' abilities. Primary outcomes of campus recreation programs include enhancing students' learning experiences and improved quality of campus life" (Schneider et al., p. 34). Much like varsity athletic programs, the order and magnitude of the aforementioned considerations are likely to vary from one campus to another and especially between intramural and club sports. For instance, accessibility is the most likely consideration to drive the design and implementation of intramural sport programs, whereas sport clubs are likelier to blend the three.

Sport clubs. Sport clubs are unique in that they are predominately student run and structured to accommodate different levels of participation ranging from general members to the chief operating officer of the club. Because many sport clubs operate in a resource-scarce environment, the availability, and practices, of administrators and coaches may be inconsistent. Further, because the ratio of students to administrators is likely high, student leaders may receive a disproportionate amount of support, through education and training, compared to the general members of any given club. Thus, if members seek a higher degree of involvement through the various leadership positions required to maintain a club, they may see a greater return in various developmental domains as they learn the skills necessary to lead and manage their peers (Dugan, Turman, \& Torrez, 2015; Flosdorf, Carr, Carr, \& Pate, 2016; Haines $\&$ Fortman, 2008). Other unique features of club sport stem from their competitive level and intake process. 
While some clubs might fall in the elite sport category, most are likely to fall somewhere on a spectrum between participation and performance given that they might value both. Thus, each club may implement its own intake process that emphasizes athletic ability and aptitude, desire to learn and participate, or both. Additionally, participation in sport clubs comes subsequent to enrollment at an institution, is predominately voluntary, and can be terminated at any time without serious opportunity cost (Warner \& Dixon, 2013). In this instance, voluntary refers to "the idea that one was not forced nor pressured to be part of the club or to show up at functions, but they continued their membership because they wanted to be there and were personally invested" (Warner \& Dixon, 2013, p. 291). In other words, once a student joins a sport club, their continued involvement is not compulsory. This leaves students with relative flexibility to determine how much time they devote to their sport club in relation to other relevant curricular and extracurricular endeavors.

The sport club ecology resembles that of varsity sport programs to some degree. Individual participants are likely to be influenced by their teammates, club leaders, recreational sport administrators and, for some, a coach or coaches. Like varsity programs, some clubs are also regulated beyond specific campus regulations by various sport governing bodies, although these bodies tend to be more specialized than the NCAA. Examples include the National Collegiate Water Ski Association (NCWSA), National Collegiate Club Golf Association (NCCGA), or the National Intercollegiate Running Club Association (NIRCA).

Intramurals. Of the three formal sport environments discussed in this paper, intramural sport unquestionably serves the greatest number of students. However, the type and degree of development that participation can facilitate is debatable given that intramural sport is also the least formal of the three. If the student-administrator interaction is limited in the sport club environment, it is almost non-existent within the context of intramural sport. With the exception of student employees and intramural officials, participants in intramurals are unlikely to interact with a recreational sport administrator unless they display deviant behavior beyond the scope of what their peers are able to deal with. This translates to very little intentionality with respect to facilitating an environment that promotes developmental outcomes commensurate to the number of participants. The biggest benefit of intramural sport is that it provides students with a social and physical outlet that leaves ample time to devote to other curricular and extracurricular activities around campus.

\section{College Student Development Research in Sport}

The similarities and differences among formal sport contexts provide fruitful areas for inquiry. However, due to various constraints (i.e., university, discipline, community, NCAA), scholarly investigation of these contexts, particularly comparisons amongst them remains extremely limited (Coakley, 2008). Of the studies on intercollegiate athletics prior to 2008, Coakley noted that fewer than one-fifth of them examined athletes' experiences, instead focusing predominately on "organizational issues" (p. 22). And while Coakley does not address research on recreational sport 
programs directly, some of the constraints he identifies, specifically those that undervalue the importance of sport as a context for study, also apply to those programs. Looking at studies published since 2008, it appears some have worked to answer Coakley's call for examination of the role of sport in individual college student development, but the range of questions being asked and the approaches used to answer them remains narrow.

The authors of the current paper identified 11 studies examining student development in both varsity $(f=8)$ and recreational sport $(f=3)$ environments. Of the nine that explicitly identified their theoretical framework, all used some combination of theoretical frames designed by Astin, Chickering, or Kuh (Andrassy, Svensson, Bruening, Hum, \& Chung, 2014; Comeaux, Speer, Taustine, \& Harrison, 2011; Dugan, Turman, \& Torrez, 2015; Folsdorf et al., 2016; Forrester, 2015; Gayles \& Hu, 2009; Gayles, Rockenbach, \& Davis, 2012; Huntrods, An, \& Pascarella, 2017; Navarro \& Malvaso, 2015). This observation is not meant to diminish the work of these scholars; on the contrary their work is integral to broadening our understanding of both sport contexts. Instead, it is meant to highlight the central issue of this paper, that there is a need to diversify the theoretical frameworks used to ask and answer questions within these environments. Not only would this enhance our understanding of participants experiences, it would also provide a more comprehensive overview of areas of congruence and incongruence between sport programs and the educational institutions they represent.

Further limiting our conception and understanding of the sport context in American higher education is the lack of research between sports and between sport contexts. For example, Warner and Dixon (2013) noted:

much of the sports literature has assumed that sporting environments are uniform or homogenous by comparing sports participants to nonparticipants and not looking at variations within these groups; that is, such studies treat all sporting environments and participant experiences as if they were consistently identical. (p. 286)

This approach overlooks contextual features that are distinct from one sport to another (e.g., football and baseball), gender differences within the same sport (e.g., men's and women's basketball), or contextual differences driven by competitive emphasis (e.g., varsity soccer and club soccer). This lack of disaggregation is evident in research in both varsity and recreational sport environments.

\section{The Concept of College Student Development}

Literature on college student development represents a distinctive subset of research in human development and is rooted in debates dating back to the early $20^{\text {th }}$ century regarding the purpose of American higher education and the proper approach for educators and administrators to adopt when working with college students (Patton, Renn, Guido, \& Quaye, 2016). The first formal philosophical guidance came 
in the form of the 1937 Student Personnel Point of View and its 1949 expansion. These documents prescribed a comprehensive approach to working with students as individuals with unique needs both within and outside of the classroom (American Council on Education, 1994a, 1994b). Under this premise, various scholars began extending the work of pioneering developmental theorists, like Jean Piaget and Erik Ericson, into the college and university context to examine how students develop during their time on campus and how to maximize this development through intentional efforts on the part of student affairs professionals (Patton et al., 2016).

Though scholars have proposed numerous definitions for student development, this paper will proceed with the following: "a process of more or less gradual change resulting in (what can be reconstructed as) one or more qualitatively different stages for which the prior stages are necessary conditions" (van Haaften, 1996, p. 18). It is also important to note that there is no single theory capable of providing universal insight into student development and it is therefore necessary to consult multiple theoretical domains to gain a comprehensive understanding of how students develop and the factors that help or hinder that development. Table 1 provides an overview of the domains to be discussed in this paper along with corresponding theories that fall within that domain.

Stage theories, like many of those discussed in this paper, provide scholars with two distinct but interrelated approaches to the study of development within the con-

Table 1

Student Development Domains

\begin{tabular}{|c|c|c|}
\hline $\begin{array}{l}\text { Developmental } \\
\text { Domain }\end{array}$ & Primary Concern & Examples \\
\hline Person-Environment & $\begin{array}{l}\text { Characteristics } \\
\text { of developmental } \\
\text { environment; role of } \\
\text { the individual in own } \\
\text { development; role of } \\
\text { educators to foster } \\
\text { development }\end{array}$ & $\begin{array}{l}\text { - Theory of Student Involvement (Astin, } \\
\text { 1984) } \\
\text { - Theory of Challenge \& Support (Sanford, } \\
\text { 1967) } \\
\text { - Human Ecology Theory (Bronfenbrenner, } \\
\text { 1979) } \\
\text { - Person-Environment Theory (Holland, 1997) }\end{array}$ \\
\hline Psychosocial & $\begin{array}{l}\text { Interpersonal and intra- } \\
\text { personal developmental } \\
\text { outcomes }\end{array}$ & $\begin{array}{c}\text { - Lifespan Development (Erikson, 1959) } \\
\text { - Ego Identity Statuses (Marcia, 1966) } \\
\text { - Theory of Identity Development } \\
\text { (Chickering, 1969) } \\
\text { - Theory of Women's Development } \\
\text { (Josselson, 1973) } \\
\end{array}$ \\
\hline Cognitive-Structural & $\begin{array}{l}\text { Epistemological and } \\
\text { moral developmental } \\
\text { outcomes }\end{array}$ & $\begin{array}{l}\text { - Theory of Cognitive Development (Piaget, } \\
\text { 1952) } \\
\text { - Theory of Intellectual and Ethical } \\
\text { Development (Perry, 1968) } \\
\text { - Women's Ways of Knowing (Belenky et al., } \\
\text { 1986) } \\
\text { - Theory of Moral Development (Kohlberg, } \\
\text { 1976) } \\
\text { - Theory of Women's Moral Development } \\
\text { (Gilligan, 1982) }\end{array}$ \\
\hline
\end{tabular}


text of American higher education. First, there is the logical progression of stages that allow researchers to reconstruct and characterize where individuals are in their own developmental journey. These stages are described in the following way:

... rather like a road map, showing a limited number of relevant features and deliberately leaving out much other information ... [to highlight] a certain developmental pattern, stressing certain aspects at the expense of others. Because of different theoretical interests, different reconstructions are possible in the same area without falsifying each other (van Haaften, 1996, p. 27).

In other words, the stages outlined in a specific theory are not meant to be applied to individuals universally, but rather provide a template for comparison to understand where someone is in their own development and where they might be headed next.

The second approach, which is more typical for researchers to adopt, focuses more on describing and explaining how individuals move from one stage to another. If we consider stages as destinations, then this approach can be characterized as examining an individuals' journey from one stage to the next. The primary concern in this approach is understanding the contextual experience of the individual within the framework of stages prescribed by the theory. Two things are important to consider when using this approach. First, it is highly individualized. If a theory prescribes four stages of development in a specific domain, transition from one stage to another may lack uniformity from one person to the next. For example, while one individuals' transition might proceed progressively (i.e., 1-2-3-4), another's may be less homogenous (i.e., 1-2-3-2-3-4). Second, an individual's transition between stages can be "smooth and continuous" or "abrupt and discontinuous" (van Haaften, p. 23) depending on the environment and what triggers development from one stage to another.

With these considerations in mind, the following section provides an overview of each domain in Table 1 with a brief explanation of some of the more broadly applied theories that fall within them.

\section{Student Development Theories}

The following sections aim to provide a streamlined overview of various theoretical approaches and considerations with respect to college student development. It is worth noting that some of these theories were designed specifically in and for the college environment, while others were designed more broadly and have since been successfully applied to social and educational settings.

\section{Person-Environment Theories}

Person-environment theories focus on the development that results from the interplay between individuals and the various environments to which they are exposed. Dewey (1916), applying this concept to education, argued that all parties (e.g., faculty, staff, students) must actively participate to optimize education and that special attention should be given to the environment in which education takes place. Lewin 
(1936) echoed these sentiments, explaining that "every psychological event depends upon the state of the person and at the same time on the environment, although their relative importance is different in different cases" (p. 9). That is, individual behavior $(B)$ can be viewed as a function of both the person $(P)$ and the environment $(E)$ (i.e., $B=f(\mathrm{P}, \mathrm{E})$, Lewin, 1936). Environmental factors impacting student development may include the size and type of institution (e.g., large public vs. small private), the focus of the curriculum and faculty (e.g., research vs. liberal arts), campus culture, and/or friend groups.

Individual development is not unique to the college setting given that "most young people will experience conflicts that challenge their perspectives and subsequently spur their progress" (Long, 2012, p. 51), be it through college enrollment, military service, or the work force. Person-environment theories, therefore, aim to examine the unique features of the higher education environment, the educator's responsibilities in shaping that environment, and the role of the individual in their own development. Given that both formal sport environments fall within the broader scope of the college environment, these theories provide sport scholars with frameworks to understand the implications for where students spend their time and energy and the type of environment that staff, coaches, and administrators produce.

Holland's Person-Environment Theory (1997) focuses on vocational satisfaction by suggesting that individuals can be characterized within various personality types (i.e., realistic, investigative, artistic, social, enterprising, conventional) and that satisfaction is likelier when the vocational environment compliments an individual's personality. This relationship is, to some extent, cyclical in that the more dominant a personality type is, the more likely it is to shape the overall environment and, thus, attract more individuals that embody similar characteristics. Despite its original focus on the vocational environment, the archetypes and constructs proposed within the theory have applications in other social and educational environments (Patton et al., 2016).

Bronfenbrenner's Human Ecology Theory (1979) provides a lens with which to view the individual and environmental factors influencing individual development. The theory outlined four components (process, person, context, and time) that educators should consider when determining the impact of the environment on students' development. The context is comprised of four systems that range from proximate (i.e., microsystems) to distal (i.e., macrosystem), with meso- and exosystems between. The further the system is from the individual, the less concrete its influence on that person's development.

Astin's Theory of Student Involvement (1984) emphasizes the importance of previous experiences students bring with them into the broader higher education environment and the unique lens created by the interaction between the two. To maximize student development, Astin simultaneously stressed the importance of active involvement (through both time and energy) on the part of the student and high-quality, relatable programs on the part of educators.

Sanford's Theory of Challenge and Support (1967) underscores the necessity for students to experience challenges which in turn produce disequilibrium and pro- 
voke their development. Sanford equally stressed the importance of not over- or under-challenging students. Toward that end, Sanford advocated that educators understand how to gauge a students' readiness to deal with environmental challenges and, utilizing that assessment, produce corresponding levels of support (or challenge if none is inherently present within the environment). Too much support may lead to stagnation, while too little support (especially in the face of high levels of challenge) could cause students to stall or even regress in their development.

Utilizing these theories to examine the formal sport environment provides researchers with both qualitative and quantitative factors to consider, particularly relative to college student development. For instance, using student involvement theory allows researchers to examine where students are allocating their time (i.e., quantitative) and energy (i.e., qualitative) to determine the implications for their overall development. Sanford, Holland, and Bronfenbrenner provide frameworks for examining the influence of educators in particular environments and at different strata of those environments.

The theories in this domain, then, expand the current over-reliance on investigations based in student involvement theory. Instead, leveraging the breadth of these theories, the following are examples of questions toward college student development in various sport contexts that might be explored using theories in the person-environment domain. What are the implicit and explicit messages resonating from the sport environment and how do these impact conceptualizations of development at both the individual and a systemic level? How are participants in different sport contexts spending their time and energy and what are the developmental implications of these allocations? How might administrators shift or shape the sport environment toward non-athletic outcomes without sacrificing athletic outcomes? What are students' roles in shaping the sport environment; their own development? How does this differ among varsity, club, and intramural sport? How do staff, coaches, or administrators in various contexts gauge students' readiness to meet certain challenges present in the broader university environment? Does this vary systemically according to context (varsity, club, intramural)? If so, what are the implications for change? How do staff, coaches, or administrators avoid over-supporting students to a debilitating degree? What factors in a sport context facilitate dependence and independence?

Person-environment theories, then, have strong potential for inquiry in this area. However, these theories are less focused on the more micro or nuanced outcomes of individual development. For answers to those questions one must turn to theories within the other developmental domains.

\section{Psychosocial Theories}

Psychosocial theories focus on the convergence of psychological and social factors that form one's conception of "how to define themselves, their relationships with others, and what to do with their lives" (Patton et al., 2016, p. 283). These theories tend to focus more on interpersonal and intrapersonal developmental outcomes and are arranged in stages similar to those described earlier. As Erikson (1959) explained, "earlier crystallizations of identity can become subject to renewed conflict, 
when changes in the quality and quantity of drive, expansions in mental equipment, and new and often conflicting social demands all make previous adjustments appear insufficient" (p. 124).

Erikson $(1959 ; 1994)$ extended the concept of development beyond simply the interaction of the person and the environment, postulating that there were also internal psychological processes and external social influences that determined an individuals' development. Erikson described development from childhood to late adulthood in eight stages differentiated by "turning points." The first four stages (Basic Trust versus Mistrust, Autonomy versus Shame and Doubt, Initiative versus Guilt, Industry versus Inferiority) described the journey through early childhood into adolescence and early adulthood. In stage five (Identity versus Identity Diffusion) individuals gain independence and typically begin the process of forming their own identity. If certain factors (e.g., cognitive development, societal pressure) are lacking, individuals may experience confusion or lack bearing in their identity development.

The final three stages (Intimacy versus Isolation, Generativity versus Stagnation, Integrity versus Despair) described how individuals progressed into later adulthood. Each of these stages was influenced by the outcome of stage five. Individuals who formed a strong sense of identity were more likely to experience intimacy, generativity, and integrity. Conversely those who struggled to form their identity may experience isolation, stagnation, and despair.

Building on Erikson's fifth stage, Marcia $(1966 ; 1976 ; 1980)$ introduced the concept of identity statuses to provide a mechanism for empirically investigating psychosocial development. These four statuses (diffusion, moratorium, foreclosure, and achievement) framed identity development within the interaction between two dimensions: exploration and commitment. Exploration, also referred to as crisis, signified an individuals' willingness to engage with competing sets of ideals to determine the most salient. Commitment referred to an individuals' personal investment and degree of confidence in their decisions. The goals and values of individuals in diffusion (low commitment, low exploration) or foreclosure (high commitment, low exploration) are influenced by external social forces (e.g., parents, educators, coaches). Conversely, those that fall within moratorium (low commitment, high exploration) or achievement (high commitment, high exploration) relied more on an internal locus of control to determine their goals and values.

One limitation of both Erikson's and Marcia's work was the inadequate scope regarding gender - an issue addressed by Josselson's Theory of Women's Development (1973). Josselson used Marcia's four identity statuses to discern differences in how women resolve or avoid identity crisis. Guardians (foreclosures) internalized the values of their parents and "sought security in relationships, chose partners who shared their perception of family life, and were psychologically tied to the centrality of family" (Patton et al., 2016, p. 294). Drifters (diffusions) were difficult to characterize because they lacked exploration and commitment for various reasons (e.g., psychological trauma, indecision, passive participation in their own lives).

Searchers (moratoriums) similarly embodied their parents' values but were pushed into exploration when they encountered other options. Women in this catego- 
ry tended to avoid identifying with their mothers while simultaneously romanticizing their fathers. Pathmakers (achievers) broke with their childhood values and formed multiple, diverse identities. These women were more concerned with self-affirmation than outside approval, basing their personal relationships on mutual need rather than social mores.

Finally, Chickering and Reisser (1993), expanding the scope of Chickering's (1969) earlier work, suggested that students traverse seven vectors (see Figure 1) integral to their overall identity development. Students begin by developing competence. In this vector students acquire new interpersonal, intrapersonal, and physical skills shaped by the educational and social environment. As students develop greater competence, they also gain confidence in their abilities and lay the foundation for successive vectors. From here, students move into one or more of three vectors: (a) managing emotions, (b) moving through autonomy toward interdependence, or (c) developing mature interpersonal relationships.

In the managing emotions vector students gain greater awareness and regulation of their own emotions and learn how to contextualize their emotional responses to various social situations. Moving through autonomy requires individuals to learn problem solving skills to handle various situations independent of authority figures they may have relied on previously. During this process students gain emotional and instrumental independence and ultimately come to understand the need for interdependence, rather than dependence, on those around them. Students in the developing mature interpersonal relationships vector learn to first tolerate and eventually appreciate others based on their differences. Additionally, these individuals develop a capacity for healthier intimacy.

As students grow and develop in these various areas, they move into the establishing identity vector and begin to establish a stronger overall sense of identity. In this vector individuals develop a more secure self-concept, both internally and within the context of feedback from others, and understand where they fall in the greater social, historical, and cultural landscape. In the final two vectors, developing purpose

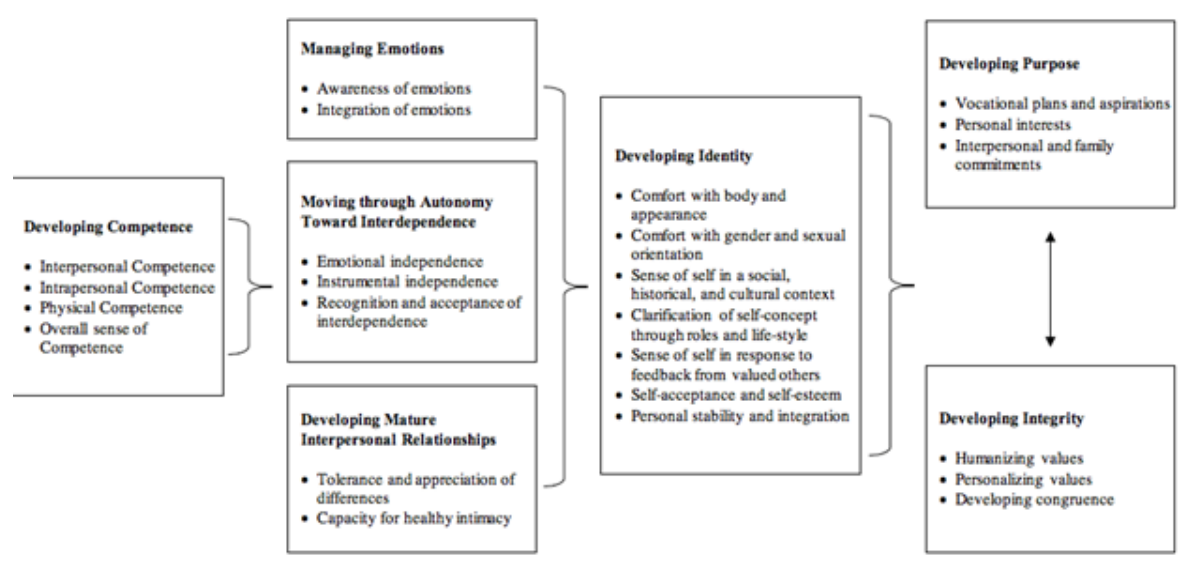

Figure 1. Chickering and Reisser's vectors (Adapted from Patton et al., 2016). 
and developing integrity, students begin to align their career goals, personal interests, and behaviors with their internal values and goals. The likelihood of students engaging with the first four vectors during their time on campus is higher than the last three, although some students may graduate having fully developed integrity and their sense of purpose.

These theories allow researchers to understand how individuals understand themselves, both internally and externally, in relation to their social settings. The following are examples of questions regarding development that might be answered using psychosocial theories. What role does sport participation play in how students develop various non-athletic aspects of their identity (e.g., racial, spiritual/faith, sexual)? How do socialization practices in various sport settings impact students' interpersonal relationships with athletes and non-athletes? How do socialization strategies impact students' intrapersonal self-concept? How does this role vary based on sport context? How does sport participation build transferable skills that will be beneficial for future employability, and how does this vary by context? Are there factors related to club vs intramural vs varsity sport that promote or hinder this type of development? Does an individual's role as an athlete create conflict with other non-athletic roles they occupy? Is this conflict experienced differently for varsity vs club sport athletes? In what ways and how is this relevant to development? What role do various types of athletic participation play in promoting the development of autonomy within a collaborative, team-based environment?

\section{Cognitive-Structural Theories}

Similar to psychosocial theories, cognitive-structural theories are organized into hermeneutic stages that build upon one another and provide insight into how students derive experiential meaning. However, theories in this domain are concerned with how individuals develop meaning-making processes to improve their epistemic and moral reasoning.

Cognitive-structural theories examine the epistemological and ethical "structures that shape how people view their experiences" (Patton et al., 2016, p. 275). Developmentally, this is important because the orientation of one's meaning-making will ideally shift from externally to internally driven processes as students are exposed to novel and increasingly complex information and environments. These theories provide insight into the ways that students receive and interpret information and how that information is subsequently applied to their worldview and actions. This has applications and implications both within and outside of college sport environments.

Many of the theories in this domain build from Piaget's (1952) pioneering work on the cognitive differences between children and adults. Piaget operated under the assumption that children were not merely less competent thinkers than adults but instead structured the processes in their thinking in completely different ways. His Theory of Cognitive Development was comprised of four stages (sensorimotor, preoperational, concrete operational, and formal operational) that built on an increasingly complex catalog of schemas which he defined as "a cohesive, repeatable action 
sequence possessing component actions that are tightly interconnected and governed by a core meaning" (p. 7). As individuals are presented with novel environmental stimuli (e.g., experiences, information), they either assimilate those stimuli into existing schemas, or restructure those schemas to accommodate the new information and return to a state of cognitive equilibrium.

Piaget's work sparked two streams of inquiry within the cognitive-structural domain: epistemological and moral development. Epistemological development is concerned with the underlying cognitive structures that shape how individuals decipher implicitly and explicitly held assumptions about the world around them (Boom, 1996). It determines which sources an individual deems legitimate for taking in and creating new knowledge about the world. Moral development, while related, employs cognitive structures in a different way. Korthals (1996) identified four interwoven cognitive and emotional abilities related to morality: 1) perspective taking ability in social settings, 2) the ability to legislate one's own moral norms, 3) the ability to discreetly apply those norms, and 4) the ability to choose the moral norms to which one conforms.

Epistemological development. Perry (1968) extended Piaget's (1952) work into the context of higher education and shifted his focus toward the cognitive transition from adolescence to adulthood. The Theory of Intellectual and Ethical Development is concerned with the cognitive complexity that individuals develop when presented with mutually exclusive information. Opting for positions instead of stages, Perry found that individuals began from a position of duality (i.e., viewing the world in opposing absolutes) where information is derived almost exclusively from authority figures and individuals adhere to the notion that a correct answer exists for any situation. As they are exposed to increasingly dissonant information, individuals begin to transition from dualism to multiplicity. These individuals may initially hold mutually exclusive ideas as equally true but eventually begin to shift their orientation from receivers of expert knowledge to independent thinkers.

As individuals become more comfortable with the ambiguity of multiplistic thinking, the need for underlying support for their arguments becomes more evident and they begin to transition into relativism where opinions from diverse sources no longer carry the same weight. Because ambiguity is often accompanied by feelings of unease, it is possible that some will try to deflect from their cognitive development. Deflections may manifest in one of three ways: (a) temporizing (i.e., stalling forward movement), (b) escape (i.e., abandoning the responsibility inherent in moving from one stage to the next) or (c) retreat (i.e., a return to dualism due to overstimulation).

One area where Perry's (1968) theory was lacking was in the level of inclusiveness with respect to the sample used to formulate the theory's tenets. Patton et al. (2016) pointed out that "attempting to generalize from a study of primarily traditionally aged white males at a prestigious institution in the late 1950 s is risky and unwise. Cautious use [. . . ] in relation to women, people of color, and other minoritized groups is advisable" (p. 330). Belenky, Clinchy, Goldberger, and Tarule (1986) worked to remedy this situation, at least to some degree, with their Theory of Women's Ways of Knowing. The authors opted for five perspectives in favor of 
stages: (a) silence, (b) received knowledge, (c) subjective knowledge, (d) procedural knowledge, and (e) constructed knowledge.

From the perspective of silence, they argued women were highly dependent on authority figures, tending not to express their own thoughts and viewing decisions as either right or wrong. These women were likely to have experienced some type of physical or emotional abuse. The other four perspectives differed in the level of confidence women had in their voice. In the received perspective, individuals take in information and adapt their behaviors accordingly, but lack the confidence to shape their own thoughts and opinions. As women progressed into the subjective perspective, they came to understand that their views did not necessarily have to align with those of authority figures, but they still lacked the confidence to externalize their own opinions. Those in the procedural perspective began to not only trust their own voice, but also to vocalize that voice to others without fear of repercussion. Finally, those women who fell into the constructed perspective understood the importance of listening to others' voices while not losing their own voice. These individuals saw knowledge creation as a collaborative process between themselves and those around them.

The following are examples of questions that might be answered using epistemological theories. For each question, it is implied that it would be asked within and between various sport contexts, exploring how differences in the structure and implementation of sport in that context intermingle with both the questions and the participant outcomes. How does the administrator-student relationship in various sport environments impact students' epistemological development and, if it does, in what directions and to what degrees? Under what conditions can sport participation lead to cognitive regression? Are sport environments epistemologically at odds with the educational environment? If so, why and how and what makes them so? How does sport participation in its various forms influence how students make meaning of their experiences (or vice versa)? How can readily available emotionally charged experiences in sport be used to help students learn and practice meaning-making? Do higher level cognitive structures impact athletic performance? How does this vary by sport, demographics, and sport structure? Could higher levels of cognitive reasoning provide a competitive edge (i.e., decision making at an integral moment of the game)?

Moral development. Also encompassed in the cognitive-structural domain are theories that deal with students' moral development. Similar to Perry (1968), Kohlberg (1976) based his moral development work on Piaget's (1952) earlier theories on cognitive development, focusing his attention first on adolescent boys before shifting to college students. His Theory of Moral Development established six justice-oriented stages (heteronomous morality; individualistic, instrumental morality; interpersonally normative morality; social system morality; human rights and social welfare morality; morality of universalizable, reversible, and prescriptive general ethical principles) to explain the progression of individuals' moral development.

In the first stage, right and wrong are determined by the rules set forth by authority figures and the goal is to avoid negative consequences. In subsequent stages mo- 
rality becomes more ambiguous. In stage two, the concept of fairness is introduced and individuals view morality in terms of weighing their own interests against the interests of others. Individuals in stage three are still influenced by external factors and view morality in terms of being a good person to those closest to them. In stage four individuals gain an understanding of broader societal constructs that govern the actions of those around them and aim to uphold those constructs. When individuals arrive at stage five, there is a shift toward the greater good and understanding that morality often relies on agreements between the individual and others. The final stage, for which Kohlberg lacked empirical evidence, requires individuals to learn to balance all points of view and provide equal consideration for each of them to try to arrive at universally applicable principles.

Consistent with other early theories in the student development literature, Kohlberg's theory was fundamentally flawed in terms of generalizability because it only considered moral development from a justice perspective and focused exclusively on men, though it should be noted that he was receptive to these criticisms and made efforts to correct them in his later work (Korthals, 1996). Gilligan (1982) worked to remedy this situation with her Theory of Women's Moral Development. She shifted the focus of morality from a justice orientation to an ethic of care, outlining three levels (orientation to individual survival, goodness as self-sacrifice, and the morality of nonviolence) with two accompanying transition periods (from selfishness to responsibility and from goodness to truth). Each level articulated the relationship of the individual to others, while the transitions emphasized changes to the sense of self. In level one, individuals focused only on themselves and found it difficult to differentiate their wants from needs. From this self-centered position, individuals transition to level two where they seek social acceptance, sometimes at their own expense, and, in some cases, the final level where the wants and needs of both the self and others are considered equally.

Again, with emphasis on exploring similarities and differences among college sport contexts, the following are examples of questions that might be explored using moral development theories. What impact do various forms of sport participation have on students' formulation of justice? What factors within the sport context inform that formulation? What impact does moral development have on how students formulate an ethic of care? In what ways do various forms of sport participation serve as a microcosm of broader morality and what impact does this have on an individual's moral development? In what ways can various forms of sport participation encourage deviance and what impact does that have on an individual's moral development? What factors within the sport environment encourage or discourage deviance? 


\section{Conclusion}

This paper draws attention to the various sport environments that exist within American higher education and echo the sentiments of Warner and Dixon (2013) in their call for studies examining "sport participant experiences within and between contexts" (p. 286). While these contexts are inextricably linked by their origins, their present-day structures and implementations vary dramatically and provide interesting areas of inquiry to better understand the place of each in higher education and in sport. Gaining an understanding of largely ignored environments (i.e., sport clubs) could lead to the promotion of those settings as valuable developmental contexts. Additionally, it is important for scholars to understand the similarities and differences among these contexts in order to discern the benefits and drawbacks that might result from participation and ultimately inform ways to improve college student development.

We argue that present-day structures, combined with underlying philosophical considerations and tensions within various sport contexts, likely shape the general approach toward college student development within each environment. Without empirical investigation, which is currently lacking across the literature base, we hesitate to suggest which sport context is likelier to facilitate or inhibit individual development. Therefore, it is imperative that we explore integrated approaches to college student development both within and between contexts to fully explain what and how and why the sport context matters in shaping student development outcomes.

Simultaneously, the preceding sections illustrate both the breadth and nuance of developmental areas of inquiry within American collegiate sport that could be explored with a greater understanding of the theoretical frames available as lenses. In this, we hope to challenge sport scholars to continually expand the questions they ask of and about sport in higher education. Broadening the conception of college student development allows scholars to consider both athletic and non-athletic outcomes that have largely been overlooked in formal sport environments to this point (e.g., epistemological and moral development).

Specifically, this paper provides an overview of college student development, various developmental domains, some of the fundamental theories that fall within those domains, as well as potential questions that one might generate using those theories. By expanding the conceptualization of college sport and student development our aim is to advance the ways that sport is studied in higher education environments, how that inquiry informs the design and implementation of various sport programs and the impact of those programs on individual participants. 


\section{References}

Adler, P., \& Adler, P.A. (1987). Role conflict and identity salience: College athletics and the academic role. The Social Science Journal, 24(4), 443-455.

American Council on Education. (1994a). The student personnel point of view (SPPV). In A.L. Rentz (Ed.), Student affairs: A profession's heritage. ( $2^{\text {nd }}$ ed., pp. 66-77). Lanham, MD: University Press of America. (Original work published 1937)

American Council on Education. (1994b). The student personnel point of view (SPPV). In A.L. Rentz (Ed.), Student affairs: A profession's heritage. ( $2^{\text {nd }} \mathrm{ed}$., pp. 108-123). Lanham, MD: University Press of America. (Original work published 1949)

Anderson, A. J., \& Dixon, M. A. (2019). How contextual factors influence athlete experiences of team cohesion: An in-depth exploration. European Sport Management Quarterly, 19(30), 353-372.

Andrassy, E. J., Svensson, P., Bruening, J., Huml, M. R., \& Chung, M. (2014). The role of organizational capacity in student-athlete development. Journal of Intercollegiate Sport, 7(2), 218-244.

Astin, A. W. (1984). Student involvement: A developmental theory for higher education. Journal of College Student Personnel, 25(4), 297-308.

Ayers, K., Pazmino-Cevallos, M., \& Dobose, C. (2012). The 20-hour rule: Student-athletes time commitment to athletics and academics. The Virginia Journal, 33(1), 22-27.

Belenky, M. F., Clinchy, B. M., Goldberger, N. R., \& Tarule, J. M. (1986). Women's ways of knowing: The development of self, voice, and mind (Vol. 15). New York, NY: Basic Books.

Beyer, J. M., \& Hannah, D. R. (2000). The cultural significance of athletics in US higher education. Journal of Sport Management, 14(2), 105-132.

Boom, J. (1996). Cognitive development. In A. W. van Haaften, M. Korthals, \& T. E. Wren (Eds.), Philosophy of development: Reconstructing the foundation of human development and education (pp. 101-117). Berlin, Germany: Springer Science \& Business Media.

Bronfenbrenner, U. (1979). The ecology of human development. Cambridge, MA: Harvard University Press.

Brubacher, J. S., \& Rudy, W. (1997). Higher education in transition: A history of American colleges and universities ( $4^{\text {th }}$ ed.). New Brunswick, NJ: Transaction Publishers.

Chen, S., Snyder, S. \& Magner, M. (2010). The effects of sport participation on student-athletes' and non-athletes' social life and identity. Journal of Issues in Intercollegiate Athletics, 3(1), 176-193.

Chickering, A. W. (1969). Education and identity. San Francisco, CA: Jossey-Bass, Inc. 
Chickering, A., \& Reisser, L. (1993). Education and identity ( $2^{\text {nd }}$ ed.). San Francisco, CA: Jossey-Bass, Inc.

Coakley, J. (2008). Studying intercollegiate sports. Journal of Intercollegiate Sports, $1(1), 14-28$.

Coakley, J. (2015). Assessing the sociology of sport: On cultural sensibilities and the great sport myth. International Review for the Sociology of Sport, 50(4-5), 402-406.

Comeaux, E., Speer, L., Taustine, M., \& Harrison, C. K. (2011). Purposeful engagement of first-year Division I student-athletes. Journal of the First-Year Experience \& Students in Transition, 23(1), 35-52.

Dewey, J. (1916). Democracy and education: An introduction to the philosophy of education. Norwood, MA: Norwood Press.

Dugan, J. P., Turman, N. T., \& Torrez, M. A. (2015). When recreation is more than just sport: Advancing the leadership development of students in intramurals and club sports. Recreational Sports Journal, 39(1), 37-48.

Erikson, E. H. (1959). Identity and the life cycle: Selected papers. New York, NY: International Universities Press

Erikson, E. H. (1994). Identity and the life cycle. New York, NY: Norton.

Flosdorf, M. L., Carr, B. H., Carr, J. W., \& Pate, J. R. (2016). An exploration of the sport club president's experience. Recreational Sports Journal, 40(2), 106-119.

Gayles, J. G. (2009a). The student athlete experience. New Directions for Institutional Research, 2009(144), 33-41.

Gayles, J. G. (2009b). The influence of student engagement and sport participation on college outcomes among division I student athletes. The Journal of Higher Education, 80(3), 315-333.

Gayles, J.G. (2014). Engaging student athletes. In Student engagement in higher education: Theoretical perspectives and practical approaches for diverse populations (pp. 209-220). New York, NY: Routledge.

Gayles, J. G., \& Hu, S. (2009). The influence of student engagement and sport participation on college outcomes among Division I student athletes. The Journal of Higher Education, 80(3), 315-333.

Gayles, J. G., Rockenbach, A. B., \& Davis, H. A. (2012). Civic responsibility and the student athlete: Validating a new conceptual model. The Journal of Higher Education, 83(4), 535-557.

Gilligan, C. (1982). In a different voice: Psychological theory and women's development. Cambridge, MA: Harvard University Press.

Haines, D. J., \& Fortman, T. (2008). The college recreational sports learning environment. Recreational Sports Journal, 32(1), 52-61.

Holland, J. L. (1997). Making vocational choices: A theory of vocational personalities and work environments. Odessa, FL: Psychological Assessment Resources.

Huntrods, C. S., An, B. P., \& Pascarella, E. T. (2017). Impact of intercollegiate athletic participation on leadership development. Journal of College Student Development, 58(2), 198-214. 
Hyatt, R. W. (1977). Intramural sports: Organization and administration. St. Louis, MO: Mosby.

Jayakumar, U. M., \& Comeaux, E. (2016). The cultural cover-up of college athletics: How organizational culture perpetuates an unrealistic and idealized balancing act. The Journal of Higher Education, 87(4), 488-515.

Josselson, R. E. (1973). Psychodynamic aspects of identity formation in college women. Journal of Youth and Adolescence, 2(1), 3-52.

Kohlberg, L. (1976). Moral stages and moralization: The cognitive-developmental approach. In T. Lickona (Ed.), Moral development and behavior: Theory, research and social issues (pp. 31-53). New York, NY: Holt, Rinehart and Winston.

Korthals, M. (1996). Moral development. In A. W. van Haaften, M. Korthals, \& T. E. Wren (Eds.), Philosophy of development: Reconstructing the foundation of human development and education (pp. 118-133). Berlin, Germany: Springer Science \& Business Media.

Lewin, K. (1936). Principles of topological psychology. New York: McGraw-Hill.

Long, D. (2012). Theories and models of student development. In L.J. Hinchliffe \& M. A. Wong (Eds.), Environments for student growth and development: Libraries and student affairs in collaboration (pp. 41-55). Chicago, IL: Association of College \& Research Libraries.

Marcia, J. E. (1966). Development and validation of ego-identity status. Journal of Personality and Social Psychology, 3, 551-558.

Marcia, J. E. (1976). Identity six years after: A follow-up study. Journal of Youth and Adolescence, 5(2), 145-160.

Marcia, J. E. (1980). Identity in adolescence. Handbook of Adolescent Psychology, $9(11), 159-187$.

Navarro, K., \& Malvaso, S. (2015). Synthesizing research on the contemporary student-athlete experience: Implications and recommendations for NCAA student-athlete development programming. Journal of College and Character, 16(4), 263-269.

Nite, C., Singer, J. N., \& Cunningham, G. B. (2013). Addressing competing logics between the mission of a religious university and the demands of intercollegiate athletics. Sport Management Review, 16(4), 465-476.

Patriksson, G. (1995). Scientific review part 2. In Vuori et al. (Eds.). The significance of sport for society - health, socialisation, economy: A scientific review. Strasbourg: Council of Europe Press.

Patton, L. D., Renn, K. A., Guido, F. M., \& Quaye, S. J. (2016). Student development in college: Theory, research, and practice. San Francisco, CA: Jossey-Bass, Inc.

Perry, W. G., Jr. (1968). Forms of intellectual and ethical development in the college years: A scheme. New York: Holt, Rinehart, \& Winston.

Piaget, J. (1952). The origins of intelligence in children (Vol. 8, No. 5, p. 18). New York: International Universities Press. 
Ridpath, B. D. (2018). Alternative models of sports development in America: Solutions to a crisis in education and public health. Athens, $\mathrm{OH}$ : Ohio University Press.

Rubin, L. M., \& Moses, R. A. (2017). Athletic subculture within student-athlete academic centers. Sociology of Sport Journal, 34(4), 317-328.

Sanford, N. (1967). Where colleges fail: A study of the student as a person. San Francisco, CA: Jossey-Bass, Inc.

Schneider, R. C., Stier Jr, W. F., Kampf, S., Haines, S., \& Wilding, G. E. (2005). Reporting structure and job satisfaction of collegiate campus recreation directors. Recreational Sports Journal, 29(1), 33-41.

Schulenkorf, N., Sherry, E., \& Rowe, K. (2016). Sport for development: An integrated literature review. Journal of Sport Management, 30(1), 22-39.

Snyder, E., \& Waterstone, K. (2015). An examination of Division III small college athletics: President and commissioner influence and change in athletic philosophy. Journal of Contemporary Athletics, 9(3), 195-210.

Southall, R. M., Hancock, K. L., Cooper, C. C., \& Nagel, M. S. (2009). College World Series broadcast: "They are What They Are". Journal of Sports Media, 7(2), 41-60.

Southall, R. M., \& Nagel, M. S. (2008). A case-study analysis of NCAA Division I women's basketball tournament broadcasts: Educational or commercial activity?. International Journal of Sport Communication, 1(4), 516-533.

Stewart, R. E. (1992). A brief history of the intramural movement. Recreational Sports Journal, 17(1), 12-14.

van Haaften, A. W. (1996). The concept of development. In A. W. van Haaften, M. Korthals, \& T. E. Wren (Eds.), Philosophy of development: Reconstructing the foundation of human development and education (pp. 13-30). Berlin, Germany: Springer Science \& Business Media.

Warner, S., \& Dixon, M. A. (2013). Sports and community on campus: Constructing a sports experience that matters. Journal of College Student Development, 54(3), 283-298.

Warner, S., Dixon, M. A., \& Chalip, L. (2012). The impact of formal versus informal sport: Mapping the differences in sense of community. Journal of Community Psychology, 40(8), 983-1003.

Wolverton, B. (2008). Athletes' hours renew debate over college sports. The Chronicle of Higher Education. Retrieved from https://www.chronicle.com/article/ Athletes-Hours-Renew-Debate/22003 